\title{
Family structures and restructures in Romanian society. Parental alienation syndrome
}

\author{
Raluca Silvia Matei, Ph.D. \\ Ovidius University Constanța, The Faculty of Psychology and Educational Sciences \\ ralum74@yahoo.com
}

Rodica Gabriela Enache, Ph.D.

Ovidius University Constanța, The Faculty of Psychology and Educational Sciences rodicaenache3@gmail.com

\begin{abstract}
In this paper we describe some problems of the Romanian families in contemporary society: marital satisfaction, psychological and social implications of divorce and parental conflicts and the parental alienation syndrome.
\end{abstract}

Keywords. divorce and parental conflicts, parental alienation syndrome

\section{Introduction}

1. Metamorphosis of the family in contemporary society, implications on marital and parental satisfaction

The family imposed itself as a central theme of social thinking of the nineteenth century. The choice of the partner, the morphological transformations of the family, the marital relations and the types of family functioning were the subject of the first studies of the 1960s, 1970s. Based on the study of the interactions within the family, different types of couples and family functioning were highlighted, following the degree of differentiation of the roles according to sex, the group's privilege of the fusion or autonomy, the opening or not of the group to the outside world.

In the '80s and the '90s, other terms appeared: male-female relationships in the family, domestic roles and habits, family socialization and educational strategies, consequences of the separation and of the returns in the couple, transmissions (heritage, memory) and intergenerational relationships, parenting support, housing and residential trajectories, family political regulation.

Due to the progress made by family sociology, there is now a better understanding of family functions (between cohabiting and non-cohabiting parents), power relations and domestic routines, family trajectories, couple formation, marital roles and gender differences, family relationships with other institutions (school, social services, the labour market or housing), the mediating role of the parental network, the relationships and transmissions between generations, the way of articulation between the family and the provident state. 
As sociologists Boudon Raymond, Cherkaoui Mohamed, Valade Bernard, (2009) point out, certain aspects of family life are required to be explored: the production of family norms (equity, exchange), the perception and experience of birth and death, the consequences of medical assisted birth on the establishment of the relationships of the family group members, the marital conflicts and the ruptures, the types of family culture and their practices, the consequences of the new technologies.

Each person tends towards the archetypal (male-female) structure based on complementarity and, therefore, the search for the partner with whom we can develop on a sexual, affective, mental and spiritual level becomes an important process of life.

Finding the right partner leads, in most cases, to couple formation and marriage. Marriage is an interpersonal process of becoming and maturing the individual as personality, of awareness, redirection and achievement of unconscious tendencies, impulses and affinities. The couple is a bipolar structure in which the partners are satisfied, stimulated, supported, developed and accomplished as biological, affective and social individuals, one through the other. (I. Mitrofan, N. Mitrofan, 1994).

Spousal marital satisfaction refers to the absence of conflicts and to the subjective impression of happiness that the two spouses have. In other words, it represents a state of emotional, physical, spiritual and intellectual well-being and cannot be reduced to the mere fulfillment of certain needs or false needs.

Beth A. D. (1997) defines marital satisfaction as a subjective, individual impression of certain specific components of the marital relationship. Marital satisfaction is an attitudinal variable and is viewed as a continuum from high satisfaction to high dissatisfaction.

Couple satisfaction is a subjective problem and is not felt with the same intensity by both partners, they have different perceptions, both regarding the degree of marital satisfaction, but also with regard to certain more or less important aspects of their life together. A couple may see the relationship as very satisfying, while someone from the outside may see the relationship as extremely unsatisfactory. Murray, Holmes, and Griffin (1996) show that perceiving one's partner as appropriate increases the level of relational satisfaction. They showed that having optimal opinions about the partner regarding different aspects of social interactions determines the perception of the relationship as a whole being more satisfactory. Over time, more research has been conducted to establish factors related to relational satisfaction. This led to the identification of a large number of such factors associated with the satisfaction felt by the partners in the couple.

Many studies have emphasized the importance of two factors in marital satisfaction: communication and commitment. Communication promotes mutual exchange and understanding. Commitment motivates the partners to work on building a creative and satisfying couple relationship.

S. Coltrane (2004) identify the following factors on which marital satisfaction depends on: fidelity $(93 \%)$, understanding $(86 \%)$, satisfactory sex life $(75 \%)$, children $(59 \%)$, common interests $(52 \%)$, money (41\%), socio-cultural similarity $(25 \%)$.

The interpretation of these results must be done carefully because even though money is considered important by only $41 \%$ of the subjects, they are also the most frequent source of conflicts and misunderstandings. On the other hand, over half of the subjects consider that the presence of children is a factor of marital satisfaction, but they are also a reason for parental conflicts.

The indicators considered to be "subjective", with an essential impact in optimizing family life are as follows:

- the socio-affective climate, 
- emotional and sexual well-being,

- authenticity and completeness of communication between partners and their children,

- maintaining a dynamic balance between fusion and psychological autonomy,

- the fluency of intergenerational borders,

- the coherence and the consensus of the models of conjugal and parental role offered to children in the education process,

- the degree of comfort and mental security, resulting from the feeling of family belonging, as an antidote to loneliness and abandonment,

- the mental and somatic health of family members,

- the ability to maintain and transmit spiritual models with positive, psychosocial values (Mitrofan I., Ciupercă C., 1997).

According to Mucchielli R., marital satisfaction also depends on satisfying conditions outside the intimacy, such as: self-satisfaction, lifestyle in general, relationships with other people outside the couple's relationship, relationships at work, etc. (Muchielli R., 1974)

Eckstein D. and Cohen L. (1998) identified 21 specific factors that are associated with relational satisfaction, which can be grouped into 3 categories: communication, empathy and the third is a combined category consisting of sincerity and negotiation.

In order to perform a classification, they identified the following categories of variables of marital satisfaction: similarity, personality factors, cognitive factors, intimacy and sexual satisfaction, previous experiences and living conditions, attachment style. Similarity in terms of age, income, education and social environment often makes it easier to establish a good relationship with the other. People who are different may also get along very well, but those who are similar often feel closer, more connected to one another, more capable of mutual understanding and empathy. (Haas A., Haas K., 1990)

Within the conjugal couple, the relationship involves the intervention of the personality with all its components and levels.

Depending on self-confidence, one spouse's positive attitude towards the other is also shaped. The better the self-image, the less internal and external conflicts exist. Some studies show that the impact of the husband's behaviour on the wife is much greater than in the reverse case, which means that the conciliatory attitude and self-confidence of the husband are more important for marital happiness.

Another important personality trait in achieving a high level of marital satisfaction is respect. It is preferable that the two spouses have a common opinion on the definition of respect and honor it. Personal dignity and self-respect are the essential premises of respect towards one's partner. The reciprocity of this feeling is very important. In the category of personality traits we also include the affective maturity of the spouses. Spouses whose relational satisfaction is maintained over time present at the moment of marriage emotional maturity. In achieving marital happiness, the emotional maturity of the husband seems to be more important than the one of the wife. Masculinity-femininity is another dimension of personality that conditions relational satisfaction. Adequate representations of self in masculine and feminine terms lead to better self-esteem and more harmonious marital relationships, to acceptance and exercising of gender roles. Some studies have highlighted the importance of female characteristics in determining marital satisfaction; they act in the following way: the more sensitive, responsible, and affectionate the individual, the more satisfied with his or her couple relationship he/she would be. The positive attitudes of the husband regarding his wife in the first years of marriage are very important for the adaptation of the woman to the couple life. 
Family it is one of the main socializing institutions in which the child learns the social norms and values and becomes able to interact with the other members of the society.

Socialization within the family has several components: normative (through which the main social norms and rules are transmitted to the child), cognitive (through which the child acquires skills and knowledge necessary for acting as an adult), creative (through which creative thinking and giving adequate answers capacities are formed), in new and psychological situations (which develops the affectivity that is necessary for the relationship established with their parents, with their future partner, with their own children), as argues Mihăilescu I. (2003). Family socialization has been the subject of further theorizations of Parsons' structuralfunctionalism. These allowed to highlight educational styles related to forms of family life and to induce different conceptions regarding the child and his/her success, including within families with the same socioeconomic level.

\section{Psychological and social implications of divorce and parental conflicts}

„The marital system based on expressive needs and less on the instrumental ones (economically-productive, training and professionalizing the children, the pressures of the group and the extended family) leads to a greater freedom of official dissolution of the couples in need, followed by the choice of a new partner or the possibility to opt for an alternative nonmarital life (cohabitation, single parent family, loneliness and sexual freedom). Cultivating expressive needs is possible due to macrosocial changes, which have made the individual potentially independent of the family. In other words, the functions and nature of the family have changed: socialization and education are now provided by public institutions, as well as health. Even the function of emotional support and affectivity is, to some extent, substitutable by peer groups, friends, colleagues” (Iluț, P., 2005, pg. 173)

In the traditional society the cultural meanings of parenting were as follows:

a) Morality: being a parent is considered a moral obligation. Being a parent demonstrates morality, not being a parent means rejecting divine authority. Not having children is immoral.

b) Responsability: being a parent means fulfilling a civic obligation, is a direction of civic responsibility, not being a parent means avoiding responsibility, the lack of children shows irresponsibility.

c) Sexual identity and competence: being a parent demonstrates acceptance of the gender and demonstrates sexual competence, not being a parent demonstrates a rejection of the gender and involves sexual incompetence.

d) Marriage: parenting gives meaning to marriage, it implies marital satisfaction and prevents divorce. Not being a parent decreases the value of marriage, increases the chances of divorce and leaves room for marital dissatisfaction.

e) Normality and mental health: parenting indicates mental health, social maturity and personal stability. (Veevers, J. E. 1973)

Being a parent is the most challenging and most rewarding experience that life offers you, raising a child involves social and emotional maturity but also taking responsibility for the rest of your life. The first years of the child's life when he/she discovers, understands and assimilates especially through the family the principles and rules of the world he/she lives in are extremely important and that is why parents need to use positive methods of growth and education to form a balanced personality of their children.

In the contemporary society we are witnessing a degradation of the parental state, many of the children being separated from their parents both for economic reasons (immigrant parents), but also for psychological or social reasons due to divorces or parental abandonment. We 
therefore witness a proliferation of the phenomenon of conflict and parental alienation. The marital conflict that is based on anger is associated with filial aggression and the externalization of behavioral problems, thus both parents and children experiencing difficulties in regulating negative affections. Exposure to strong conflicts of any kind in the family increases the psychological suffering experienced by children, which in turn affects the child's sense of security. (Boza M., 2016). Exposure to observed or hidden conflicts affects the parental relationship and consequently has a negative impact on the child's adaptation. Regardless of the marital status, parental conflicts are much more harmful to the child's well-being, leading to an increased risk of behavioral problems, psycho-social problems and unsatisfactory adaptation. (Boza M., 2016)

\section{Transnational families}

During the economic reforms, new family configurations have emerged, such as the "transnational family" as a result of the massive population exodus and as a by-product of globalization, urbanization, economic restructuring in combination with the improvement of transport and information technologies.

Analysis of the transnational family has been undertaken in various theoretical frameworks. Baldassar, Baldock and Wilding (2007, apud. Boza 2016) outlined a "transnational care model, focusing on the complexity of the factors that influence parenting practices: the ability to engage in distance care and assistance (financial, access to technology, time, mobility, etc.), the cultural feeling of being obliged to provide care and to cover the needs of others (perception of need and debt), the negotiated family commitments and characteristics of family relationships".

Among the effects of emigration of parents with a major impact on the psychological and emotional stability of children, their abandonment to relatives or even to social protection institutions is identified. From a psychological point of view, the abandonment represents "the action of leaving a person, of not granting the necessary care, the lack of concern for his/her fate" (Pop L.M., 2002).

From a social point of view, the abandonment of the child is defined as the action by which a child is abandoned, left without care by his/her parents or by the persons who have legal maintenance obligations towards the child. In a paper published in 2017, Matei R. shows that the affective needs of the young people in the care institution, being greater than their possibilities of satisfying the restrictions of life in the collective, formed against the background of biological and mental vulnerability, trigger stresses of collective nervousness, marked by crisis of affection (crying, anger), demanding attitudes (jealousy, possessiveness). These manifestations are consequences of the abandonment neurosis, due to the maternal affective deficiency as well as the neglect of the child by the adult, the maternal substitute.

\section{Parental alienation syndrome}

In the contemporary society there are many changes and restructuring of parental roles, as social roles, some of them explaining a pathology of preventable social behaviours.

Parental alienation is the process and the result of the psychological manipulation of a child in showing fear, disrespect or unwarranted hostility towards a parent and/or other family members (Lorandos, Bernet \& Sauber, 2013). It is a distinct form of psychological abuse both to the child and to the rejected family members, which occurs almost exclusively in association with family separation or divorce, especially when legal action is involved.. (Baker, Bone \& Ludmer, 2014)

Parental Alignment Syndrome (PAS) is a term conceived by psychiatrist Richard Gardner and presented in his 1985 paper to describe a set of distinctive behaviors that he 
claimed to be manifested by the children who were psychologically manipulated into showing fear, disrespect or hostility towards one parent and/or other family members - usually by the other parent and during child custody disputes. (Gardner, 1985)

The present paper aims to bring to public attention the phenomenon of parental alienation in the context of contemporary family restructuring, precisely to prevent these situations of child abuse due to economic and social causes and with long-term implications on the development of the personality of young people.

The concept of a parent trying to separate his/her child from the other parent as a punishment or part of the divorce has been described since the 1940s, but Gardner was the first to define a specific syndrome. In his 1985 paper, he defined parental alienation syndrome as "... a disorder that occurs primarily in the context of child custody disputes. Its main manifestation is the campaign to denigrate the child against the parent, a campaign that has no justification. The disorder comes from the combination of indoctrinations made by the alienating parent and the child's own contributions to criticizing the alienated parent." (Gardner, 1985)

He also stated that indoctrination can be deliberate or unconscious on the part of the alienating parent (Gardner, 2004). Gardner initially believed that parents (usually mothers) made false allegations of child abuse and sexual abuse against the other parent (usually fathers) in order to prevent further contact between them. (Caplan \& Cosgrove, 2004).

While Gardner initially described the mother as an alienator in $90 \%$ of the cases of parental alienation syndrome, he later stated that both parents were equally likely to practice this behaviour (Gardner, 2002).

Considering all these aspects that the current Romanian family goes through, there is an evident need of the counselling and parental psychological assistance services performed by specialists in interdisciplinary teams consisting of psychologists and social workers both to treat some "wounds" that affect the child's personality: rejection, abandonment, humiliation, betrayal and injustice as well as to prevent dysfunctional parental behaviours.

\section{References}

[1] Baker J.L., Ludmer M.B.B., (2014), The High-Conflict Custody Battle: Protect Yourself and Your Kids from a Toxic Divorce, False Accusations, and Parental Alienation, New Harbinger Publications

[2] Beth A. D., (1997), Factors of marital satisfaction among African American couples and Nigerian male/ African American female couples, Hournal of Cross- Cultural Psychology, https://journals.sagepub.com/doi/abs/10.1177/0022022197281004

[3] Boudon R., Cherkaoui M., Valade B. (2009), Dictionary of sociological thinking, Polirom Publishing House

[4] Boza M., (2016). The influence of gender and ethnic essentialization on intergroup attitudes in preschool children, Proceedings of the 1f European conference on Developmental Psychology, 1\4edimond, 213-219.

[5] Caplan, P. J., \& Cosgrove, L. (Eds.). (2004), A project of the association for women in psychology. Bias in psychiatric diagnosis. Jason Aronson.

[6] Coltrane S., (2004), Research on Household Labor: Modeling and Measuring the Social Embeddedness of Routine Family Work, Journal of Marriage and Family, https://onlinelibrary.wiley.com/doi/full/10.1111/j.1741-3737.2000.01208.x

[7] Eckstein D., Cohen L. (1998), The Couple's Relationship Satisfaction Inventory (CR51): 21 Points to Help Enhance and Build a Winning Relationship, https://journals.sagepub.com/doi/abs/10.1177/1066480798062015 
[8] Gardner, R. A. (1985). Recent trends in divorce and custody litigation. Academy Forum, 29(2),3-7

[9] Gardner, R. A. (2004). The relationship between the parental alienation syndrome and the false memory syndrome. The American Journal of Family Therapy, 32, 79-99. doi:10.1080/01926180490424181

[10] Iluţ, P. (2005), Sociopsychology and anthropology of the family, Polirom Publishing House, Iași

[11] Lorandos D., Bernet W., Sauber S.R.(2013), Parental Alienation: The Handbook for Mental Health and Legal Professionals (Behavioral Science and Law) Har/Cdr Edition, Springfield, USA

[12] Matei, R. S. (2017), Features of the psychological profile of adolescents in residential centers, University Publishing House, Bucharest.

[13] Mihăilescu I. (2003), General sociology, Polirom Publishing House, Iaşi

[14] Mitrofan, I., Mitrofan, N. (1994), Couple psychology elements, Șansa S.R.L. Publishing House, Bucharest.

[15] Mitrofan, I., Mitrofan, N. (1997), Psychology of relationship between gender, Alternatives Publishing House, Bucharest

[16] Mucchielli R. (1999), L'observation psychologique et psycho-sociologique, Paris

[17] Murray, Sandra L., Holmes, John G., Griffin, Dale W. (1996), The benefits of positive illusions: Idealization and the construction of satisfaction in close relationships, Journal of Personality and Social Psychology, Vol 70(1), https://psycnet.apa.org/buy/1996-01707-007

[18] Pop, L. M. (2002), The Dictionary of Social Policies, Expert Publishing House, Bucharest.

[19] Veevers, J. E. 1973, The social meanings of parenthood, "Psychiatry", 36, 291-310, DOI: $10.1080 / 00332747.1973 .11023764$ 